\title{
Vocal Technique in a Group of Middle Eastern Singers
}

\author{
Abdul-Latif Hamdan ${ }^{a}$ Reem Deeb ${ }^{c}$ Rania A. Tohme ${ }^{d}$ Hani Rifai ${ }^{b}$ \\ Sami Husseini ${ }^{b}$ Nabil Fuleihan ${ }^{b}$ \\ Departments of a Otolaryngology and ${ }^{\mathrm{b}}$ Otolaryngology - Head and Neck Surgery, American University of Beirut \\ Medical Center, ${ }^{C}$ Department of Civilization Sequence, School of Arts and Sciences, and ${ }^{\mathrm{d}}$ Department of Epidemiology \\ and Population Health, Faculty of Health Sciences, American University of Beirut, Beirut, Lebanon
}

\author{
Key Words \\ Vocal technique $\cdot$ Breathing pattern $\cdot$ Middle Eastern \\ singing
}

\begin{abstract}
Objective: We aimed to report on the vocal technique in a group of Middle Eastern singers. Subjects and Method: A total of 78 Middle Eastern singers were assessed. Demographic data included age, gender, training status and number of years of singing. All singers had laryngeal videoendostroboscopy. Description and grading of posture, tension, type of breathing, type of phonation, resonance and tone quality are reported. Proportions and means ( \pm SD) were used to describe the sample for categorical and continuous variables respectively. Associations between endostroboscopy and voice technique were determined by $\chi^{2}$ or Fisher's exact test. Results: There were 43 males and 35 females with an age ranging between 16 and 32 years and a mean of 23 \pm 4 years. Of these, $88.5 \%$ were nontrained singers and $50 \%$ had more than 3 years of singing experience. Around $80 \%$ of Middle Eastern singers rely on either thoracic or clavicular breathing. Posture was average in $68 \%$ and moderate tension was present in $63 \%$ of the cases. Two thirds had a bright voice, $61 \%$ were hypernasal and almost $46 \%$ had a strained phonation. There was a significant correlation be-
\end{abstract}

\section{KARGER \\ Fax +41 613061234 \\ E-Mail karger@karger.ch}

www.karger.com (c) 2008 S. Karger AG, Basel

1021-7762/08/0604-0217\$24.50/0

Accessible online at:

www.karger.com/fpl tween posture and tension. Conclusion: Middle Eastern singing relies more on thoracic breathing and is characterized by tension.

Copyright $\odot 2008$ S. Karger AG, Basel

\section{Introduction}

Middle Eastern singing is intimately related to the phonatory behavior of the Middle Eastern speaking voice. The articulatory behavior witnessed while speaking is very much used or similar to the one employed in singing. At times the latter is more of a lyrical rather than an operatic singing. Middle Eastern singing is a style by itself dictated by a music rich in modes known as the maqam system. This system is characterized by half steps, whole steps and quarter steps, a genre of performance distinct in its type of breathing, support and resonance. A straight tone lacking vibrato, for instance, may not be desired by Western listeners, yet is aimed at in the Middle East. Similarly, a deep husky voice in females is highly appreciated and considered a plus by many vocal teachers. Most Middle Eastern singers do not depend on years of vocal training and rather rely on personal improvisation of the performed musical piece. Many of them seem to pay closer attention to singing their music in the correct mode(s)

Abdul-Latif Hamdan, MD, FACS

American University of Beirut, Department of Otolaryngology

PO Box 11-0236

Beirut (Lebanon)

Tel./Fax +961 1 746660, E-Mail alhamdan@svclb.com 
with the addition of many ornaments, rather than paying attention to the vocal norms adopted in the teaching of the Western classical style of singing, that is in terms of posture, support and breathing [1].

On the other hand, in the pedagogy of classical singing, many years of serious and formal vocal training are spent to build and improve a singer's vocal technique and much attention is paid to correct posture and alignment. Extreme care is given to reduce tension in the upper body, neck, jaw and tongue, in order to generate efficient breathing support and control. The aim is to produce a wellsupported sound based on adequate posture and a wellsuspended larynx and characterized by a beautiful timbre and good resonance [2-4]. There are no reports in the literature describing the vocal technique of the Middle Eastern singing style in terms of posture, breathing pattern, type of phonation, tension, resonance and tone quality. This study was undertaken to report the vocal technique in a group of Middle Eastern singers that presented to the Specialty Voice Center for training.

\section{Subjects and Method}

The medical records of singers who presented to the Specialty Voice Center between 2002 and 2004 were reviewed. A total of 78 records were collected. All of these singers presented for vocal training and enhancement. Demographic data included age, gender, training status and number of years of singing. The singers were classified as trained if they had had singing lessons for more than 6 months or had a degree in music. We chose a short period, 6 months, to label a singer as trained in view of the scarcity in training.

All singers had laryngeal videoendostroboscopy, the result of which was classified either as normal in the absence of any vocal fold lesion or labeled as others in the presence of nodules, polyps, cysts or nonspecific findings such as edema and redness.

\section{Vocal Technique Evaluation}

Evaluation of the singers was retrieved from a standard form that was filled at the time of presentation during their vocal training and while performing a song they were familiar with. The singers were assessed while performing in the standing position in a quiet but not sound-treated room.

The evaluation was performed by the first author, who is a laryngologist and has many years of experience dealing with singers, and by one of the co-authors (R.D.), who has a doctorate in music from the USA, is a well-known soprano singer, is currently an assistant professor at the American University of Beirut and has been extensively involved in the training of many professional singers in the region.

The following parameters were graded and analyzed: posture, tension, type of breathing, type of phonation, resonance as hypoor hypernasal and tone quality as bright or dark. The phonation was described as breathy, flow or strained. Posture was graded as good, moderate or poor according to the extent of alignment of
Table 1. Baseline demographic characteristics

\begin{tabular}{ll}
\hline Variable & \\
\hline Mean age \pm SD, years & $23.12 \pm 3.91$ \\
Gender, \% male & 55 \\
Years of experience, \% less than 3 years & 53.8 \\
Vocal training, \% none & 88.5 \\
Stroboscopy, \% & \\
$\quad$ Normal & 75.6 \\
Nodule & 9.0 \\
Polyp & 3.8 \\
Cyst & 7.7 \\
$\quad$ Nonspecific & 3.8 \\
\hline
\end{tabular}

the head in relation to the chest, abdomen, hip, knees and feet. Tension was also graded as none, mild to moderate or severe in relation to the presence or absence of muscular tension in the neck, strap muscles, jaw, tongue and palate position during the performance. No electromyographic measurements were taken. Breathing was classified as abdominal, thoracic or clavicular based on visual observation. Nasal resonance was chosen as a vocal characteristic because this quality of sound is commonly used in Middle Eastern singers. A tone was defined or described as bright if it was brilliant or forward, whereas a tone was defined as dark when it was muffled or back positioned. Support was assessed but not reported in view of lack of a well-defined rating scale used at the time of evaluation and the lack of data on subglottic pressure to be analyzed in relation to support.

\section{Statistical Method}

Proportions and means ( $\pm \mathrm{SD}$ ) were used to describe the sample for categorical and continuous variables respectively. Associations between vocal techniques and results of stroboscopy, as well as between tension and each of posture and breathing were measured using $\chi^{2}$ or Fisher's exact test as appropriate. All analyses were conducted using SPSS, and a p value $<0.05$ was considered statistically significant.

\section{Results}

\section{Demographic Data}

There were 43 males and 35 females. The age ranged from 16 to 32 years with a mean of $23 \pm 4$ years. The majority $(88.5 \%)$ were nontrained singers and half of them had more than 3 years of singing experience (table 1 ).

\section{Laryngeal Videoendostroboscopy}

Laryngeal videostroboscopy was normal in $75.6 \%$ of the cases. The remaining ones had either polyps, nodules, cysts or nonspecific findings such as vocal fold redness or edema. This group of abnormal stroboscopic findings will be referred to as others in the text. 
Table 2. Vocal technique assessment

\begin{tabular}{|c|c|c|c|c|c|c|c|}
\hline \multirow[t]{2}{*}{ Grading } & \multicolumn{2}{|c|}{ Total } & \multicolumn{2}{|c|}{ Normal } & \multicolumn{2}{|c|}{ Others } & \multirow{2}{*}{$\begin{array}{l}\mathrm{p} \\
\text { value }\end{array}$} \\
\hline & $\mathrm{n}$ & $\%$ & $\mathrm{n}$ & $\%$ & $\mathrm{n}$ & $\%$ & \\
\hline \multicolumn{8}{|l|}{ Posture } \\
\hline Good & 15 & 19.2 & 12 & 20.3 & 3 & 15.8 & \multirow[t]{3}{*}{0.524} \\
\hline Moderate & 53 & 67.9 & 38 & 64.4 & 15 & 78.9 & \\
\hline Poor & 10 & 12.8 & 9 & 15.3 & 1 & 5.3 & \\
\hline \multicolumn{8}{|l|}{ Tension } \\
\hline None & 1 & 1.3 & 0 & 0 & 1 & 5.3 & \multirow[t]{3}{*}{0.320} \\
\hline Moderate & 49 & 62.8 & 38 & 64.4 & 11 & 57.9 & \\
\hline Severe & 28 & 35.9 & 21 & 35.6 & 17 & 36.8 & \\
\hline \multicolumn{8}{|l|}{ Breathing } \\
\hline Abdominal & 17 & 21.8 & 12 & 20.3 & 5 & 26.3 & \multirow[t]{3}{*}{0.272} \\
\hline Thoracic & 48 & 61.5 & 39 & 66.1 & 9 & 47.4 & \\
\hline Clavicular & 13 & 16.7 & 8 & 13.6 & 5 & 26.3 & \\
\hline \multicolumn{8}{|l|}{ Tone quality } \\
\hline Bright & 50 & 64.1 & 39 & 66.1 & 11 & 57.9 & \multirow[t]{2}{*}{0.587} \\
\hline Dark & 28 & 35.9 & 20 & 33.9 & 8 & 42.1 & \\
\hline \multicolumn{8}{|l|}{ Phonation } \\
\hline Breathy & 19 & 24.4 & 15 & 25.4 & 4 & 21.1 & \multirow[t]{3}{*}{0.788} \\
\hline Flow & 23 & 29.5 & 16 & 27.1 & 7 & 36.8 & \\
\hline Strained & 36 & 46.2 & 28 & 47.5 & 8 & 42.1 & \\
\hline \multicolumn{8}{|l|}{ Resonance } \\
\hline Нуро & 10 & 12.8 & 5 & 8.5 & 5 & 26.3 & \multirow[t]{3}{*}{0.062} \\
\hline Normal & 20 & 25.6 & 18 & 30.5 & 2 & 10.5 & \\
\hline Hyper & 48 & 61.5 & 36 & 61.0 & 12 & 63.2 & \\
\hline
\end{tabular}

'Others' includes nationalities such as Saudi Arabia, United Arab Emirates, Kuwait, Tunisia, Bahrain, Iraq and Morocco.

\section{Vocal Technique Evaluation}

The perception of the quality of voice was reached after a formal listening to the singer while performing a song he or she was familiar with and during his or her vocal training with the vocal teacher. With respect to the evaluation of singers with normal laryngeal stroboscopy, posture was poor in $15 \%$ and moderate in $64 \%$ of the cases. All singers had tension in their singing, with the majority being in the moderate group. Close to $66 \%$ relied on thoracic breathing and only $20 \%$ were familiar with or used the abdominal breathing. Two thirds of the singers had a tone quality described as rather bright. Around $61 \%$ had a hypernasal singing and $47 \%$ had straining in their singing voice. The evaluation of those with abnormal stroboscopy and the overall group is presented in table 2 . The singers with abnormal stroboscopy were more likely to have moderate posture, severe tension and clavicular breathing than those with normal stroboscopy. They were also more likely to have a dark tone quality and hyponasal singing. However, associations between vocal

Vocal Technique in a Group of Middle Eastern Singers
Table 3. Association between voice tension and each of posture and breathing

\begin{tabular}{|c|c|c|c|c|c|c|c|}
\hline & \multicolumn{6}{|c|}{ Tension } & \multirow{3}{*}{$\begin{array}{l}\mathrm{p} \\
\text { value }\end{array}$} \\
\hline & \multicolumn{2}{|c|}{ none } & \multicolumn{2}{|c|}{ moderate } & \multicolumn{2}{|c|}{ severe } & \\
\hline & $\mathrm{n}$ & $\%$ & $\mathrm{n}$ & $\%$ & $\mathrm{n}$ & $\%$ & \\
\hline \multicolumn{8}{|l|}{ Posture } \\
\hline \multicolumn{8}{|l|}{ Total sample } \\
\hline Good & 0 & 0.0 & 15 & 100.0 & 0 & 0.0 & 0.002 \\
\hline Moderate & 1 & 1.9 & 29 & 54.7 & 23 & 43.4 & \\
\hline Poor & 0 & 0.0 & 5 & 50.0 & 5 & 50.0 & \\
\hline \multicolumn{8}{|l|}{ Normal } \\
\hline Good & 0 & 0.0 & 12 & 100.0 & 0 & 0.0 & 0.008 \\
\hline Moderate & 0 & 0.0 & 21 & 55.3 & 17 & 44.7 & \\
\hline Poor & 0 & 0.0 & 5 & 55.6 & 4 & 44.4 & \\
\hline \multicolumn{8}{|l|}{ Others } \\
\hline Good & 0 & 0.0 & 3 & 100.0 & 0 & 0.0 & 0.393 \\
\hline Moderate & 1 & 6.7 & 8 & 53.3 & 6 & 40.0 & \\
\hline Poor & 0 & 0.0 & 0 & 0.0 & 1 & 100.0 & \\
\hline \multicolumn{8}{|l|}{ Breathing } \\
\hline \multicolumn{8}{|l|}{ Total sample } \\
\hline Abdominal & 1 & 5.9 & 13 & 76.5 & 3 & 17.6 & 0.124 \\
\hline Thoracic & 0 & 0.0 & 27 & 56.3 & 21 & 43.8 & \\
\hline Clavicular & 0 & 0.0 & 9 & 69.2 & 4 & 30.8 & \\
\hline \multicolumn{8}{|l|}{ Normal } \\
\hline Abdominal & 0 & 0.0 & 9 & 75.0 & 3 & 25.0 & 0.605 \\
\hline Thoracic & 0 & 0.0 & 23 & 59.0 & 16 & 41.0 & \\
\hline Clavicular & 0 & 0.0 & 6 & 75.0 & 2 & 25.0 & \\
\hline \multicolumn{8}{|l|}{ Others } \\
\hline Abdominal & 1 & 20.0 & 4 & 80.0 & 0 & 0.0 & 0.199 \\
\hline Thoracic & 0 & 0.0 & 4 & 44.4 & 5 & 55.6 & \\
\hline Clavicular & 0 & 0.0 & 3 & 60.0 & 2 & 40.0 & \\
\hline
\end{tabular}

'Others' includes nationalities such as Saudi Arabia, United Arab Emirates, Kuwait, Tunisia, Bahrain, Iraq and Morocco.

techniques and stroboscopy findings did not reach statistical significance. Posture, on the other hand, was related to tension in the voice, with all singers having a poor posture and moderate to severe tension in their voice (table 3). Nevertheless, no associations were found between breathing pattern and tension.

\section{Discussion}

Proper awareness of the assumed posture and breathing pattern as well as understanding the respiratory and glottal behavior of the style of singing performed is important for vocal pedagogy and adequate management 
planning of vocal problems $[5,6]$. Very little is known regarding the Middle Eastern style of singing, or at least has been reported in the literature. Middle Eastern singers often challenge themselves to follow the change of modes within a song and the difficult ornaments. Much agility is required to achieve similar tasks and excessive tension is invariably observed as a consequence. The lack of training, excessive tension, poor posture, inadequate breathing support and bad vocal habits often prevail in the singing career of many eminent singers, ultimately leading to vocal disturbances, such as contracted range, vocal fatigability, problems of transition between registers and pitch breaks.

Good posture allows the muscular components of the body to move freely and the breathing mechanism to fulfill its basic functions efficiently without any undue tension. No doubt it is much easier for the vocal apparatus to initiate phonation and for the resonators to tune the voice when the whole vocal apparatus is in proper alignment and unnecessary tension has been eliminated. Problems related to posture, such as alignment and tensional faults, may interfere with normal phonation [7]. In our study of the overall group, posture was moderate in $68 \%$, with a higher percentage having an abnormal stroboscopy. This was also reflected in the quality of the voice, which was perceived as strained in almost half of the singers. Moderate tension was present in $63 \%$ of the cases. There was a significant correlation between posture and tension. The singers with poor or moderate posture were more likely to have tension.

Breathing can modulate pitch by affecting the length and tension of the vocal folds (mechanical coupling), type of phonation by affecting glottal adduction, loudness by controlling subglottal pressure and last but not least the position of the larynx.

Tracheal pull induces an abductory force, i.e. when the lungs are inflated the pull is stronger, whereas when the lungs are deflated the pull is weaker. High lung volume is associated with less glottal adduction - hypofunctional phonation and reduced glottal attack. This has been attributed to the low position of the larynx. On the other hand, low lung volume is associated with more adduction and a harder glottal attack. This has been attributed to the high position of the larynx. Singers in general are usually consistent in their breathing pattern, which is related to their type of phonation whether support is used or not [8]. An imbalance between breathing and glottal valving may adversely affect the singer's ability to properly perform. Depending on the level of training, this may manifest itself as phonatory disorders or be masked by the singing technique. Shilling [9] distinguished 2 types of breathing support, diaphragmatic versus thoracic, and Nadoleczny [10] reported the costoabdominal type of breathing to be present in $40 \%$ of singers. In our study, the results indicated that most of our singers had a thoracic or clavicular type of breathing rather than abdomional as reported in Western singing. This can be attributed to the age of the candidates, the lack of professional training as most of them never received formal training or for very short periods if any, and last but not least to the fact that the concept of abdominal support while singing is anemic in the Middle Eastern culture. McKinney [7] described upper chest breathing or clavicular breathing as a method that is not taught but rather naturally present in untrained singers and is partially due to incorrect posture. This type of breathing may partially limit the downward movement of the diaphragm and hence limits the capacity of the lower lung area and interferes with the free function of the support mechanism. It is often associated with tension in the muscles of the chest and shoulders, which may be transmitted to the neck and laryngeal muscles. Laryngeal hyperfunction may prevail as a compensatory mechanism to poor support or inefficient breathing pattern. This may manifest itself as excessive tension in the extralaryngeal or neck musculature while singing, perceived by the vocal teacher, or as various muscle tension patterns seen on fiberoptic laryngoscopy, such as medialization of the false vocal folds and anteroposterior shortening of the distance between the petiole and posterior commissure. In our study, only $20 \%$ relied on abdominal breathing and tension was present in almost all the candidates. However, there was no significant correlation between breathing pattern and tension. Of course the style of singing and the piece performed may entail the usage of different types of breathing as mandated by the song and the training of the singer. Our study does not include data on the lung volume or subglottic pressure used during the various types of breathing in order to correlate between the type of breathing and the various types of phonation. This remains an assumption that needs further scientific demonstration.

Resonation is the process by which the vocal signal is enhanced in timbre and/or intensity by the air-filled cavities throughout the vocal tract, nose and paranasal sinuses. Factors that affect the vocal resonance include the size, shape, thickness of the walls and surface of the resonators. The most important factor influencing resonance is the length of the vocal tract, which is related to the position of the larynx. Singers in general and operatic singers in particular strive to enrich and enhance their sing- 
ing voice by developing the singer's formant. It is defined as an increase in signal intensity between the third and fourth formants. It is generated by clustering of the third, fourth and fifth formants. It seems to be attained by lowering the larynx and widening the pharynx. We have previously reported that the singer's formant was not present in the sung vowels in a group of Middle Eastern singers [11]. Other forms of resonance are associated with the nasality of the singing voice. Faults related to nasal resonance can be subdivided into excessive nasal resonance referred to as hypernasality and insufficient nasal resonance referred to as hyponasality. It is invariably very hard to reach a consensus on how much hyper- or hyponasality is desired and on what is a good tone quality. It is very much related to the style of singing and the language used in performing a song. In our study, close to $62 \%$ of our subjects had hypernasality and $64 \%$ had a bright tone quality, features that might be distinctive of or coherent with the Middle Eastern style of singing, rather than being designated as faults or pathologic.
Our study carries 2 limitations: (1) it is a retrospective study, and (2) no objective measures such as electromyography or pressure transducers were used in the collection of data. Nevertheless, in view of the large number of subjects analyzed and the homogeneity of the evaluation, this study gives us a fair description of the Middle Eastern style of singing.

\section{Conclusion}

Middle Eastern singing seems to be characterized by moderate tension, hypernasality and thoracic breathing. The asymmetry in style between Western and Middle Eastern singing does not reflect more pathology in one style versus the other, but rather reflects different vocal characteristics appraised differently by various cultures. Further research is needed to better understand the differences in the styles of singing.

\section{References}

1 Helou S: Almousika alnthriah, ed 2. Beirut, Al Hayat Press, 1961, pp 81-83.

2 Cleveland T: When hoarseness is the goal. NATS J 2001;57:47-48.

3 Edwin R: Belting 101. NATS J 1998;54:5354.

4 Gregg JW: On vibrato. NATS J 1994;50:4546.

5 Mendes AP, Brown WS, Rothman HB, Sapienza C: Effects of singing training on the speaking voice of voice majors. J Voice 2004; 18:83-89.
6 Hollien $\mathrm{H}$ : That golden voice - talent or training? J Voice 1993;7:195-204.

7 McKinney JC: The Diagnosis and Correction of Vocal Faults (revised edition). Nashville, Genevox Music Group, Broadman Press, 1982.

8 Sonninen A, Laukkanene AM, Karma K, Hurme P: Evaluation of support in singing. J Voice 2005; 19:223-237.
9 Schilling R: Untersuchungen über die Atembewegungen beim Sprechen und Singen. Monatsschr Ohrenheilkd 1925;59:51-56

10 Nadoleczny M: Untersuchungen über den Kunstgesang. Berlin, Springer, 1923.

11 Hamdan AL, Tabri D, Deeb R, Rifai H, Rameh C, Fuleihan N: Formant frequencies in Middle Eastern singers. Am J Otolaryngol 2008;29:180-183. 